\title{
How household thermal routines shape UK home heating demand patterns
}

\author{
Clare Hanmer (D) - Michelle Shipworth • \\ David Shipworth $\cdot$ Edwin Carter
}

Received: 22 October 2017 / Accepted: 12 February 2018 / Published online: 5 March 2018

(C) The Author(s) 2018. This article is an open access publication

\begin{abstract}
In homes in the UK, it is very common to operate space heating intermittently; the heating is usually switched off when the occupants are asleep at night and when they are out during the day. The strong association between heating operation and household routines leads to a morning peak in demand which, if it persists following electrification of heating, will require significant reinforcement of electricity supply networks.

This paper examines factors that underpin how heating is used in the UK. A unique dataset of heating controller settings from 337 UK allows investigation of how patterns of heating operation in individual homes contribute to daily patterns of space heating energy consumption at the group level. A mixed method approach is followed, combining quantitative analysis of data with interviews with householders.

The concept of thermal routines is introduced, bringing a time dimension to the consideration of domestic

C. Hanmer $(\bowtie) \cdot$ M. Shipworth $\cdot$ D. Shipworth

UCL Energy Institute, 14 Upper Woburn Place, London WC1H ONN, UK

e-mail: clare.hanmer.15@ucl.ac.uk

M. Shipworth

e-mail:m.shipworth@ucl.ac.uk

D. Shipworth

e-mail: d.shipworth@ucl.ac.uk

\section{E. Carter}

PassivSystems Ltd, Benyon House, Newbury Business Park,

Newbury RG14 2PZ, UK

e-mail: edwin.carter@passivsystems.com
\end{abstract}

thermal comfort and recognising that demand for space heating is linked to patterns of practices in the home, which are themselves linked to social routines, e.g. timing of work and school. The results from this study suggest that household thermal routines around 07:00 in the morning are a particularly important consideration for a transition to future energy systems with a high proportion of low carbon heat. Factors that currently limit flexibility of heating demand in the UK are identified, and the implications for a transition to low carbon heating sources are discussed.

Keywords Domestic space heating · Energy demand patterns

\section{Introduction}

Domestic space heating accounts for $11 \%$ of the UK's greenhouse gas emissions (DECC 2012), and reducing emissions from heating homes will be an important step towards achieving the UK's commitment to an $80 \%$ reduction in greenhouse gas emissions by 2050 .

The predominant type of heating in the UK is central heating from a gas boiler: $90 \%$ of homes have central heating (the vast majority with hot water circulating through radiators) and $91 \%$ of these are fuelled by natural gas (Palmer and Cooper 2014). ${ }^{1}$ Energy systems modelling suggests that it will not be possible to reach

\footnotetext{
${ }^{1}$ Judson et al. (2015) Table 1 gives an overview of the main UK domestic heating technologies
} 
2050 carbon reduction targets without a very substantial shift away from gas heating to lower carbon heat sources for example electric heat pumps or district heating from a low carbon heat source (Delta-ee 2012).

In homes in the UK during the winter heating season, it is very common to operate space heating intermittently, with the heating switched off (or setback to a much lower setpoint) when the occupants are asleep at night and out during the day. Plots of internal temperatures during the day most commonly show a pattern of peaks and troughs rather than a steady temperature (Huebner et al. 2015; Kane et al. 2015). This pattern for temperatures is reflected in power demand. The analysis by Summerfield et al. (2015) of 30-min power usage data for 567 UK dwellings states 'all quintiles exhibited characteristic morning and longer evening periods of peak power demand' (p198).

Patterns of heat demand will become increasingly important as the task of meeting peak demand periods in the UK is moved away from the gas supply system to electricity networks as the transition to low carbon heating progresses. For natural gas, the storage available as a result of the volume of the supply pipework means that demand can be 'smoothed' over the day, but electricity supply has to match demand on a second by second basis, which means that the electricity network must be designed to supply short-term demand peaks (Strbac 2008). A transition to electric heat pumps in many homes will have a significant impact on these peaks (Redpoint 2013). ${ }^{2}$

In order to manage the peaks in electricity demand, there is likely to be an increased role for demand side response (DSR) services, in which consumption patterns are modified in response to an external signal such as price (Ofgem 2016). The current focus of demand side response load management is to move electricity demand away from the evening peak (Chan et al. 2014), but it seems likely that morning peaks in electricity use will become an increasing issue as penetration of low carbon heating from electric heat pumps increases. DSR will require flexible patterns of heating operation - for example, operating a heat pump ahead of, but not during, a peak period in order to pre-heat the home. If DSR management of heating is to be successful, the altered

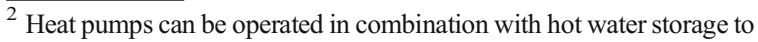
decouple supply from demand however this is not typical practice in the UK where space restrictions prevent the addition of a storage tank in many homes.
}

operation patterns must be acceptable to householders and sensitive to the diversity of occupant needs. The first step in investigating the flexibility of heating patterns is to explore how households are currently operating their heating.

This paper reports on the level of synchronicity and diversity in heating time settings for a group of homes (focusing on temporal rather than spatial diversity) and discusses the relationship between aggregate daily patterns of space heating demand and individual household running patterns.

The study is based on data supplied from PassivLiving HEAT units, controlling either oil or gas boilers. The data include records of temperature setpoints entered by the users, so it is possible to examine the interaction with the controller directly. This unique dataset means that it is possible to see exactly when the heating settings are changed, and to what value, unlike in previous studies of operating patterns (e.g. Huebner et al. 2013; Kane et al. 2015) which inferred heating controller settings from internal temperature measurements.

The next section of the paper introduces the concept of thermal routines, which is used as a framework for the study, and outlines the research traditions on which this concept draws. The following section describes the mixed method approach that was followed to investigate thermal routines, combining analysis of data from heating controllers with interviews with households. Next, findings about individual household routines and how these combine to affect aggregated energy demand patterns are discussed. The concluding section highlights the challenges that established thermal routines pose for a transition to low carbon heating.

\section{Developing a concept of household thermal routines}

The concept of thermal routines aims to represent how daily patterns of space heating demand are influenced both by rhythms of daily activities in the home and by requirements for particular internal temperatures at different times. It picks up the idea put forward by Nicol: 'most people have a daily thermal routine ... on the whole we know what thermal conditions to expect over a day or a month and we generally have strategies for dealing with them' (Nicol et al. 2012 p3) with a specific focus on routines in the home. 
This section describes how thermal routines build on two theoretical approaches (thermal comfort and social practice theory) to provide a framework for looking at space heating energy use in the dynamic environment of the home.

\section{Thermal comfort}

The long tradition of work on thermal comfort offers insights into the thermal conditions preferred by building occupants. ASHRAE Standard 55-2013 Thermal Environmental Conditions for Human Occupancy defines thermal comfort as 'that condition of mind which expresses satisfaction with the thermal environment' (ASHRAE 2013, p. 3). The 'heat balance' model of thermal comfort is based on equations for heat exchange with the environment (Fanger 1970), and relates the comfort rating reported by building occupants to six 'primary factors': air and radiant temperature, air movement, relative humidity, and an individual's clothing level and metabolic rate.

The adaptive approach to thermal comfort 'starts with the biological insight that the human being is a comfort-seeking animal who will, given the opportunity, interact with the environment in ways that secure comfort' (Humphreys and Nicol 1998). In most homes in the UK, running a central heating system is the main way that residents alter the indoor thermal environment in their homes. The adaptive thermal comfort approach recognises that operating central heating is not the only option open to residents: they have other ways to alter their thermal environment (e.g. opening a window) or adjust their personal thermal conditions (e.g. wearing more clothes). A key tenet of this approach is the principle that 'if a change occurs such as to produce discomfort, people react in ways which tend to restore their comfort'(Nicol et al. 2012, p. 8). This view of 'thermal comfort as part of a self-regulating system' (Humphreys and Nicol 1998) is particularly relevant to the management of domestic indoor environments since 'householders are usually in charge of their own comfort' (Tweed et al. 2014) with a variety of options available to them to change their environment.

Much adaptation involves changing the 'primary factors' in the heat balance equation, for instance wearing additional clothing when the temperature drops, but there is an additional psychological dimension (not included in the heat balance model) based on the occupants' perception of the opportunities available to control their conditions (Hellwig 2015) and on their expectations of typical or appropriate conditions (Nicol et al. 2012). Oseland (1995) found that his British respondents chose (and reported feeling comfortable at) lower temperatures in their homes than in the office when the heat balance approach predicted the same comfort temperature in both locations. The work of de Dear et al. (1991) in Singapore showed that preferred temperatures varied between home and office, suggesting that residents have context-specific expectations for indoor climate.

Most UK homes experience significant swings in temperature over $24 \mathrm{~h}$, and this dynamic thermal environment is very different to the static conditions investigated in much of the thermal comfort research. Findings from historic comfort studies, which have mostly taken place in climate chambers and non-domestic buildings, are therefore less directly useful to understanding how householders might adapt to and change their thermal environments.

The focus of much thermal comfort research is on measuring occupants' assessment of their thermal environment (typically self-reported thermal sensation and preference) - and less on occupants' actions to create their thermal environment, i.e. investigating what they do to achieve an acceptable state. Studying comfort response is more relevant for buildings where occupants have limited opportunities to control conditions (e.g. large office environments) than for domestic settings with adequately sized heating systems.

Practices, rhythms and routines

Social practice theory offers an explanation of how heating energy use is linked to everyday activities in the home. That there is a regular temporal pattern to many practices is highlighted in Reckwitz' frequently cited definition of practice as 'a routinised type of behaviour' (Reckwitz 2002, p. 249).

Shove and Walker (2014) point out that 'energy is used, not for its own sake, but as part of, and in the course of, accomplishing social practices'. In recent years, social practice theory has been widely applied to studies of energy demand (e.g. Shove 2003; Strengers 2013; Torriti et al. 2015). Shove et al. (2009) discuss the links between the timing of practices in the home and wider social rhythms. Heating is used to provide an appropriate thermal environment for activities in the home and so is linked to a suite of different practices 
Fig. 1 Thermal routines as a subset of household routines

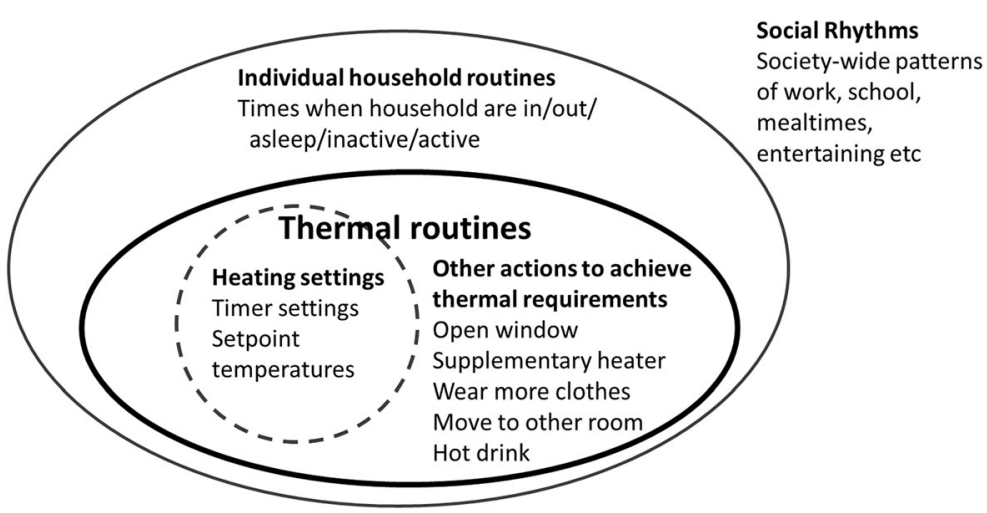

(for example getting dressed, preparing and eating meals, caring for children, watching television). Some practices may have an impact on heating demand even though they are not directly related to achieving thermal comfort. For example, opening a window to ventilate cooking odours will create extra heating demand as cold air enters the house, or the heating thermostat may be turned to a higher setting because of a need to dry laundry hung on radiators. People operate heating not just for their own thermal comfort but for that of guests, pets and (in examples quoted by Strengers et al. (2014)) 'curious' consumers such as wine collections and pot plants.

Daily patterns in energy use in the home will be influenced by patterns of everyday practices (e.g. when the occupants are out at work, or asleep) which are in turn influenced by social rhythms (Shove et al. 2009). Zerubavel points out the influence of social factors on the schedules of individuals: "parts of one's schedule are obviously going to be shared by others who belong to the same social circles' (Zerubavel 1985, p. 68).

\section{Thermal routines}

Thermal routines, as considered in this study, are defined as regular patterns in time of heating use and other actions taken to achieve thermal requirements. The term 'thermal requirements' is used rather than 'thermal comfort' to indicate that heating may be operated to satisfy requirements beyond individual thermal comfort, for example to dry laundry.

Shove makes a useful distinction between 'routine' and 'a routine': 'the term "routine" represents and describes the regularity with which a practice is enacted. (...) "a routine" like a morning routine, or the Wednesday routine, has to do with the way in which multiple practices are ordered and scheduled' (Shove 2012, p. 103). Household thermal routines follow this definition of 'a routine' and are created by regular practices in the home, which are linked to demand for space heating.

Figure 1 indicates how thermal routines include both setting heating controllers and also actions not directly linked to the central heating, such as use of supplementary heat sources in addition to the main heating system (e.g. a wood burner or electric fan heater) or wearing extra clothing. The diagram shows how thermal routines, including the operation of heating systems, are a subset of the more general set of all regular activities carried out in the home. ${ }^{3}$ The practices in individual homes are influenced by society-wide rhythms of activity.

The concept of thermal routines brings a time dimension to the normally static consideration of thermal comfort. It recognises that demand for domestic space heating is linked to patterns of practices in the home. It offers a language for talking to householders about their regular activities and how these interact with their energy use for heating.

\section{Methods}

Using the concept of thermal routines as a framework, the study investigated regular patterns in time in weekday heating operation data. Quantitative and qualitative methods were combined to investigate how daily

\footnotetext{
3 Those households unable to alter heating patterns because of technical faults or lack of access to (or understanding of) controllers may still follow routine patterns of supplementary heating, clothing or ventilation alterations.
} 
patterns of space heating demand for a group of homes relate to individual household thermal routines.

A dataset from heating controllers allowed quantitative assessment of synchronicity and diversity of heating operation times across a sample of 337 homes for an 8week period in the heating season. This allowed description of actions taken - in terms of the settings entered into heating controllers. The reasons for taking these actions were explored in interviews with seven heating users when they explained factors affecting their thermal routines. This mixed-method approach had the additional advantage that the interviews brought to light practices not anticipated by the researcher or visible in the quantitative data.

\section{Heating controller data}

Households with a PassivLiving HEAT unit are told not to set boiler on and off times, but instead to program the time they plan to wake up, go out etc. and the controller will operate the boiler to provide the temperature levels required in these periods. The user sets up an 'occupancy schedule', entering what times each day they will be IN, OUT and ASLEEP and the temperature they would like at that time. These terms are capitalised throughout the paper to indicate the controller 'occupancy' states;

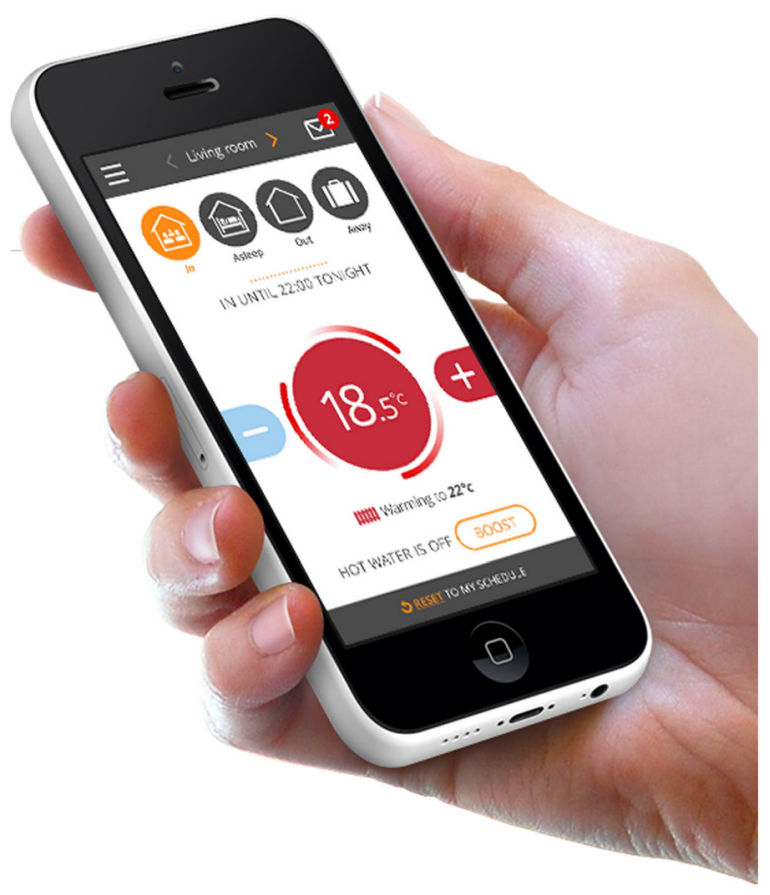

Fig. 2 Main screen for mobile phone app (source PassivSystems) these may or may not coincide with the actual times that residents are at home, out or asleep. The user can manually override the current scheduled temperature, either directly on the control unit or via a mobile phone app and web portal. Figure 2 shows a view of the app, which provides a straightforward way to change current setpoint temperature or shift between occupancy states.

The main focus of the analysis was the timing and length of IN 'occupancy' periods, since this is the period that the residents have decided they wish the heating to run as necessary to maintain their chosen thermal conditions. It should be noted that the boiler may also operate during OUT or ASLEEP periods if the temperature drops below the setpoints for those periods; this is most likely to happen if the home is poorly insulated or left unoccupied for an extended period, or if the setpoint for those periods is not much lower than the IN setpoint.

Heating controller data analysis

Data for 40 weekdays in January and February 2016, from $4 / 1 / 16$ to $26 / 2 / 16$, were analysed from controllers from 337 homes geographically distributed across the whole of the UK. The data were anonymised and no data about the buildings or residents were available.

The controller data provided by PassivSystems comprised readings for the temperature setpoint, internal temperature (measured at the unit), as well as the 'call for heat' and 'call for hot water' signals generated by the controller. This data was sampled at 5-min intervals. A total of 500 homes were randomly selected from the complete list of PassivSystems installations (which are geographically dispersed across the whole of the UK). Pre-processing was carried out to remove data sets with $>4000(6.2 \%)$ missing data points. A small number of datasets where the PassivSystems unit was not in fact controlling the heating in the home during the period of interest were removed. These homes showed a steady fall in the internal temperature over a period of at least 2 days even though the control unit was calling for heat - possibly because the boiler was faulty or out of action.

Following this pre-processing, the main analysis was carried out on data for 337 homes for 40 weekdays in January and February 2016, from 4/1/16 to 26/2/16. This period was chosen to represent part of the heating season, with no major holiday periods included. Data from weekends was excluded as the focus of the analysis was on regular routines during the week. 
The timing of the IN 'occupancy' period was inferred from the temperature setpoint data. Figure 3 shows the default operating pattern programmed in the controllers when they are installed, which shows clear steps in setpoint between IN and other periods. Since the actual setpoints are very variable between homes, visual inspection was used to determine a threshold which distinguished between the periods of highest setpoint (assumed to be IN) and other periods with relatively lower setpoints (assumed to be ASLEEP or OUT-for the purposes of the analysis, the only requirement was to distinguish between IN and 'not IN'). The data were analysed to determine the time at the beginning and end of each IN period for each home on each day.

The boiler will cut in and out as required by the control system to maintain the desired temperature so it will not be running all the time during IN periods. Figure 4 shows a typical pattern of calls for heat in which the boiler initially operates continuously until the setpoint temperature is reached and then operates intermittently to maintain temperature. In this example, the boiler starts in the morning before the setpoint rises. This shows the operation of the (optional) 'optimum start' feature of PassivSystems controllers. The principle is to start the heating up to an hour before the beginning of an IN period, so that the home has been brought close to the desired temperature at the beginning of the period.

PassivSystems controllers are not connected to energy meters so direct energy use data were not available.

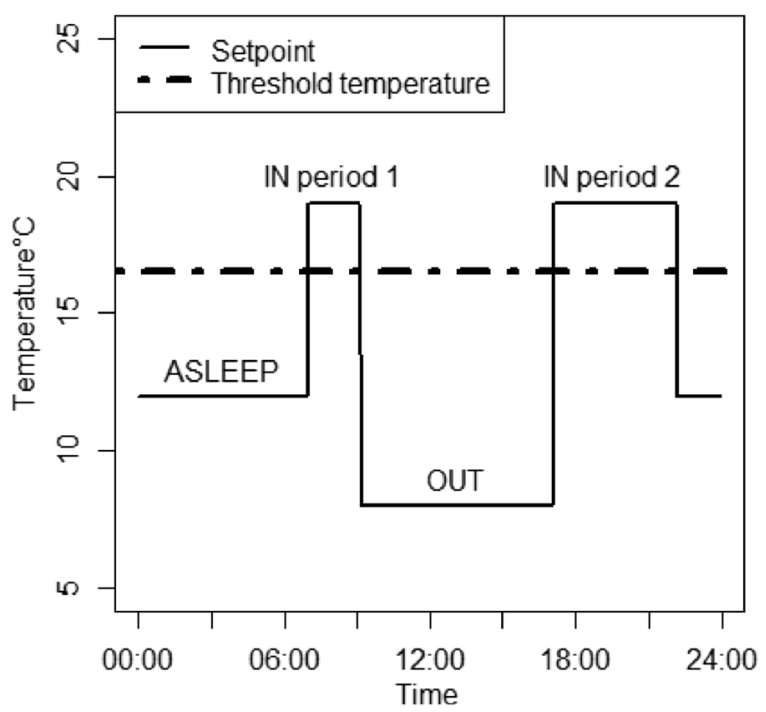

Fig. 3 PassivSystems weekday default settings, showing how threshold of $16.5^{\circ} \mathrm{C}$ distinguishes between morning and evening IN periods and those when occupancy is set to OUT or ASLEEP

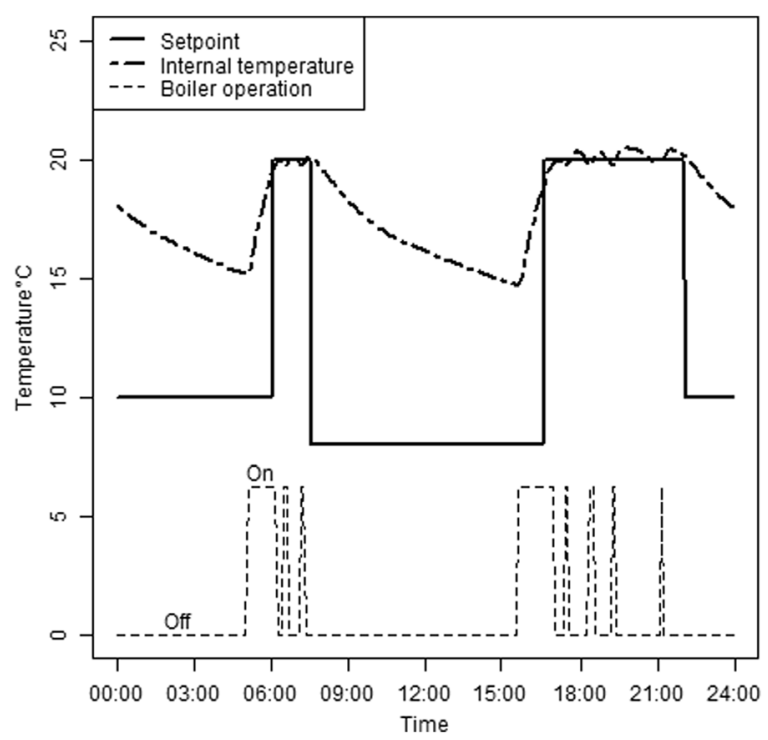

Fig. 4 Typical boiler operation pattern (Home 23319 January 2016)

The call for heat signal from the unit was used to determine the coincidence of boiler operation as a proxy for space heating demand. A boiler coincidence factor (the proportion of homes with the boiler running at the same point in time) is calculated for each 5-min period in the day. There is not a simple linear relationship between this boiler coincidence factor and the absolute level of total space heating energy demand. The boiler may modulate its heat output, and hence its fuel consumption, and may be simultaneously supplying hot water. Nevertheless, the 'call for heat' data can be used to investigate the pattern of demand over time, since increases and decreases in number of boilers running will lead to increases and decreases in the total amount of power used.

\section{Interviews}

Complementing the quantitative data analysis, the study included interviews with volunteers recruited by e-mails sent out by PassivSystems to groups of customers. Semi-structured telephone interviews were carried out with seven householders with a range of house types, location and household size. The interviewees are referred to by pseudonyms in this paper. The interviews, which were carried out in March to June 2016, included open questions about how respondents decided on time and temperature settings when setting heating controls. 
Fig. 5 Distribution of number of IN periods in day (for all homes all days). (Not matched indicates days when the number of times the heating switches on does not match the number of times it switches off, since the heating was operating in an irregular pattern which included periods running after midnight.)

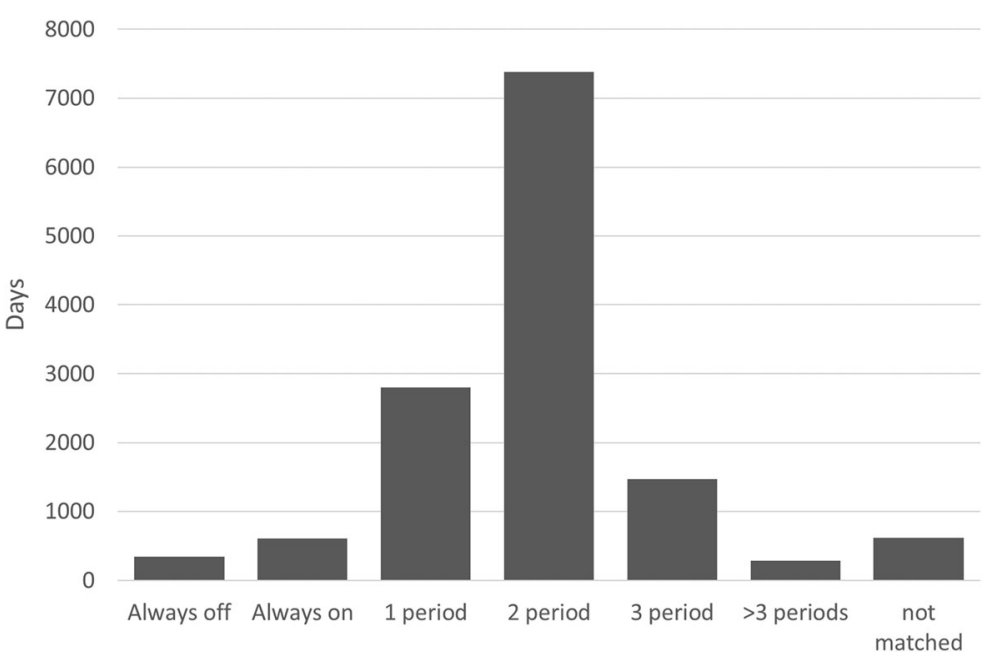

Limitations

The results from this study are not generalisable to a wider group of homes. While the PassivSystems controllers are fitted in dwellings of a wide variety of types and ages, there is no reason to expect that the sample of homes is representative of the overall UK building stock. The controllers were installed for a variety of motives, including as an option alongside solar panel installation and active choice by homeowners, so many of the users could be considered 'early adopters' rather than representative of the general population. The expectations built into the design of the PassivSystems user interface, with its 'script' (Akrich 1992) asking for an 'occupancy schedule', may shape user interaction in a way that differs from households with less sophisticated control systems and those who operate their heating manually. The optimum start feature added complexity to the analysis as different homes had different strategies for whether or not the home was heated in advance of an IN occupancy period.

The sample for interviews was small. The responses represent the point of view of only one member of each household. Volunteers who responded to the request to participate in the study may be more aware of energy use in the home than the general population.

\section{Results and discussion}

This section describes the findings from quantitative analysis of heating controller settings and the additional insights provided by interviews with householders. The link between daily patterns of space heating energy demand and the synchronicity of controller settings is discussed.

Household thermal routines as evidenced by heating controllers

Figure 5 shows the breakdown of running modes in the sample. It shows that the most common mode is to operate the heating for two periods in the day (two IN periods are set in the controller). This two period operation is in line with the default assumption of two 'demand periods' (morning and evening) commonly used in the BREDEM modelling which is a foundation for many UK building stock models (Kavgic et al. 2010; Shipworth 2013). It should be noted, however, that $45 \%$ of the $N=13,480$ days in the sample do not show two period operation.

The start and end times of weekday heating periods set in controllers were analysed to investigate the synchronicity of space heating operation. ${ }^{4}$ Table 1 shows the statistics for four time periods which are important in defining the schedule of intermittent heating operation: the start of the first IN period in the day, the start of the final IN period (for those homes with more than one operating period in the day) and the end of the final (or only) IN period in the day. The median and inter-quartile range (IQR) were used as the measures of central

\footnotetext{
${ }^{4}$ The division between days was set at midnight.
} 
Table 1 Statistics for IN heating period times

\begin{tabular}{lrccc}
\hline & $N$ & Median & IQR (min) & Mean \\
\hline First on time & 12,499 & $07: 00$ & 90 & $07: 23$ \\
Final on time & 9606 & $16: 00$ & 150 & $15: 45$ \\
Final off time & 12,478 & $22: 00$ & 65 & $21: 23$ \\
\hline
\end{tabular}

tendency and degree of variation for these parameters since (as can be seen from the histograms in Figs. 6 and 7) the distributions are not normal, and have outliers.

Figure 6, the histogram of the time at which the first IN period starts shows a concentration of starting times around 07:00. An even more synchronous pattern is seen for the end of the final IN period in the day in Fig. $7 .^{5}$

The first time the heating switches on and the last time it switches off show a clear relationship to societywide patterns that influence when people are asleep. As Shove (2009 p21) points out in a discussion of Lefebvre (2004) 'going to sleep and waking up are effectively collective processes - even for those who do them alone'.

Following the example of research linking energy use with time use studies (e.g. Torriti et al. 2015), the results were compared with the 2005 UK Time Use Survey (Lader et al. 2006). This shows that the point at which $50 \%$ of people are no longer in the 'sleep, resting' state occurs at approximately 07:10, close to the median 'heating on time' of 07:00 found in this study. The point at which half the population have gone to bed is approximately 22:50, nearly an hour later than the median final heating off time in this study. This may indicate that some householders decide to let the heating turn off and allow the temperature to start falling some time before the actual time they go to bed.

The median last heating on time - the beginning of the final heating period for days with two or more running periods - is 16:00. The histogram in Fig. 8 shows that the variation in this second time is much wider than the first on time and the difference in the inter-quartile ranges is clear in Table 1 . This is likely to

\footnotetext{
${ }^{5}$ The small number of points with final IN period ending early in the day are those with single heating periods running over midnight.
}

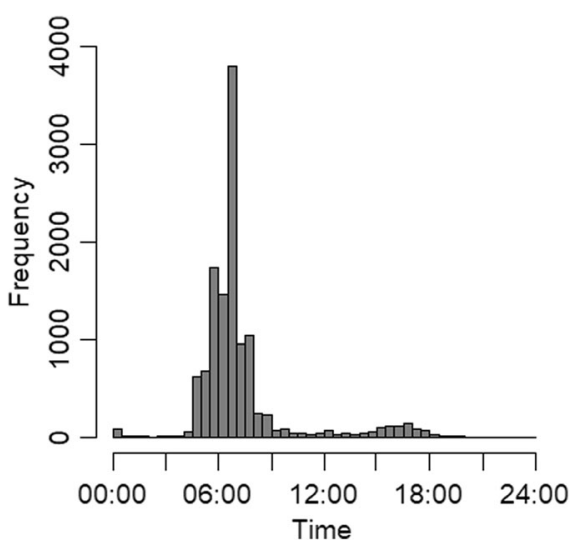

Fig. 6 Start time of first IN period in day

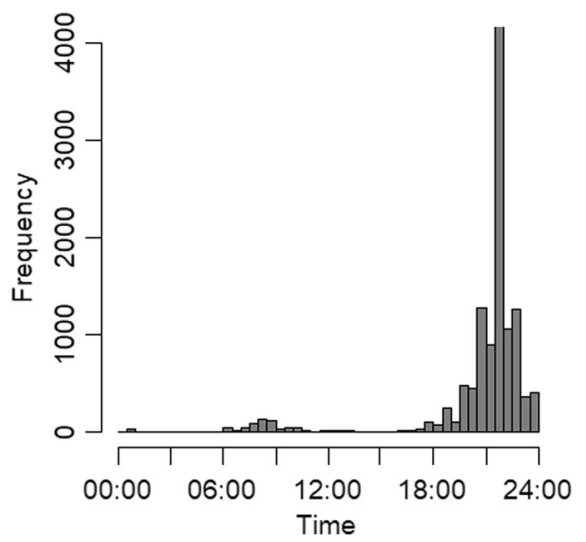

Fig. 7 End time of final IN period in day

be linked to the more variable end times (compared to the highly consistent start times) for the 'employment, study' period evident in the Time Use Survey (Lader et al. 2006).

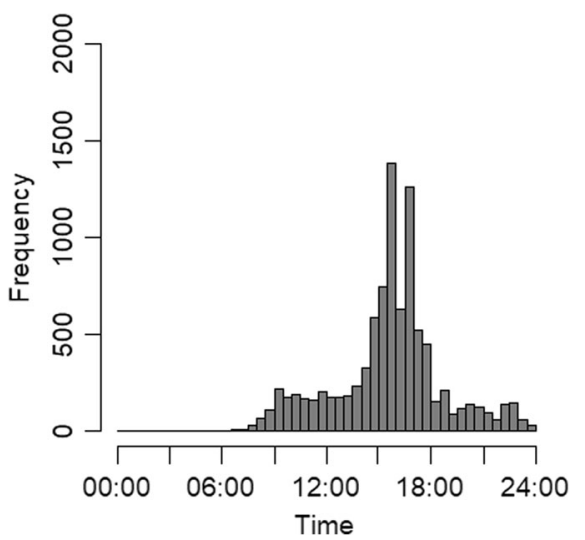

Fig. 8 Start time of final IN period in day (for days with two or more heating periods) 


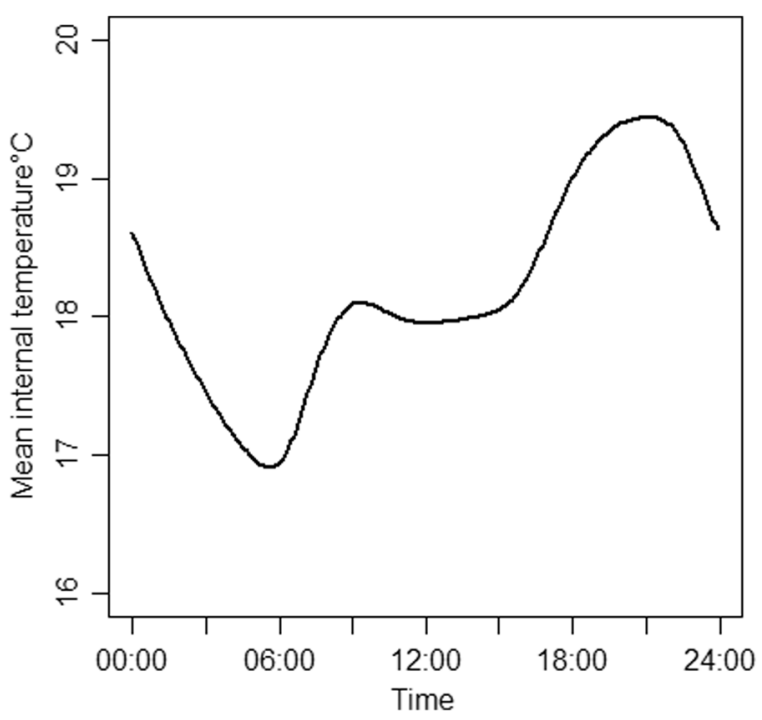

Fig. 9 Variation in internal temperature measured at controller over the day (sampled at 5-min intervals): mean across all days and all homes

The pattern of temperature during the day which results from this can be seen in Fig. 9, which shows the mean temperature (at the control unit) across all homes for all days in the sample. The mean temperature peaks in the evening, with a smaller, lower peak in the morning. This profile is very similar to the profile of the largest cluster found in Huebner et al.'s (2015) analysis of data from 275 living rooms in English homes.

Household thermal routines as described by householders

Interviews with householders enabled exploration of the extent to which heating time settings matched recollection of actual activity patterns for the households concerned, in particular the times when the occupants are asleep and out of the house. It soon became clear that, for some interviewees, heating schedules did not match actual times in/out/asleep. Eleanor is usually in the house during the day but still chooses to have two heating periods as this 'seems sensible' and she is not 'sitting round feeling the cold' during the middle of the day when she has the controller set to OUT even though she is normally in the house. John (who is a shift worker, leaving for work at variable times of day, and whose wife is often in during the day) says the default two period setting 'tends to suit us' even though there is often someone in the house in the OUT period in the middle of the day. He was not concerned about the occasions when he had to get up early and the heating was not on. Similarly, David, who sometimes has to leave for work very early in the morning, did not set the heating to come on earlier than usual on these occasions - his stated intention was to program a regular routine to suit his wife and children.

It is apparent that, at least for a proportion of this small interview sample, heating time and occupancy patterns are not the same. Their thermal routines involved heating time settings which deliver a satisfactory result for the household, even though they do not map to actual occupancy patterns of the residents. This shows how an apparently clear story about society-wide patterns becomes more complex when individual households are considered. It also questions the basic principle underlying the occupancy assumptions used in many building energy models, which assume that heating operation coincides with times when the dwelling is occupied and the occupants are not asleep (e.g. McKenna et al. 2015). Rather than matching their actual patterns of occupation, it seems that at least some users programme a two period operation schedule, because this offers an acceptable level of comfort and conforms to their expectations of how a heating system should be run.

The interviews brought to light thermal routines not visible in the data for controller settings since they did not involve operating the heating controller. Two respondents mentioned regular use of supplementary heating. John said that he and his wife frequently use a wood burner 'when it's cold' but that they will only light this in the evening and Hugh reported using the wood burner in the living room 'every evening'. One response highlighted heating energy use which was for another purpose than thermal comfort: Catherine said she sometimes increases the thermostat temperature when she has 'emergency laundry' to dry for the next day.

The interview included open questions about temperature preferences at different times and in different parts of the home. A theme mentioned by four respondents was a preference for lower temperatures in the bedroom when sleeping at night. This preference for lower temperatures when sleeping has also been noted by other researchers (Fell 2016; Owen et al. 2012). 


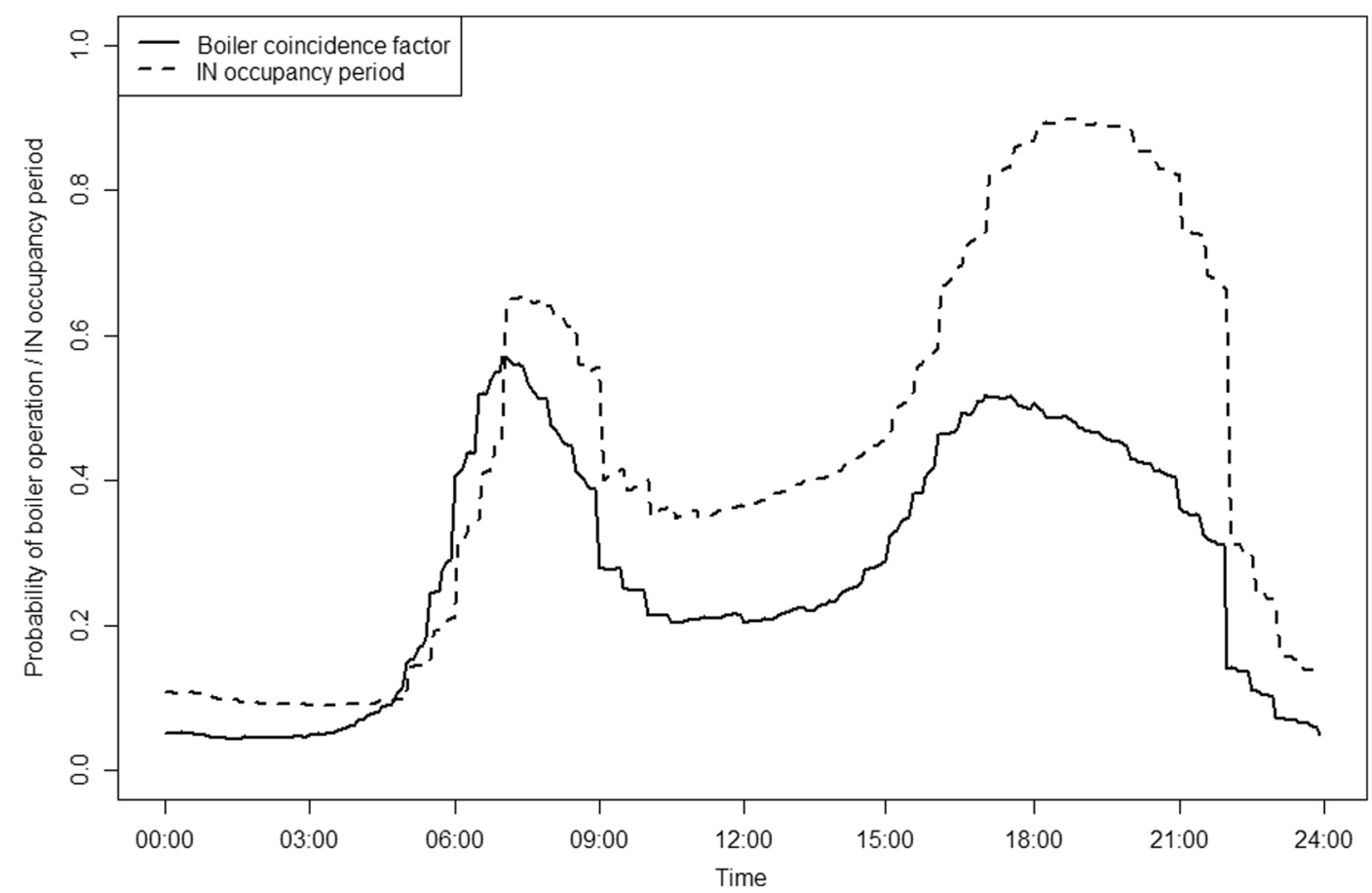

Fig. 10 Daily pattern of boiler coincidence and IN occupancy period

Social rhythms and energy demand

The final stage of the analysis was to examine patterns of weekday space heating demand for the whole sample, to investigate how the aggregation of individual household running patterns shapes the pattern of cumulative demand.

Figure 10 shows the mean for the 40 weekday period of the boiler coincidence factor (proportion of boilers running) for each 5-min period in the day. The graph shows that there are particular times of day when demand across many homes coincides. The mean proportion of homes with 'occupancy' set to IN is also plotted (as explained above, the boiler is not necessarily running continuously during IN periods). It is noticeable that both parameters have a clear pattern of morning and evening peaks. ${ }^{6}$ However, the morning peak in boiler coincidence (at 07:00) is higher than that in the evening (at 17:00), while the peak proportion of IN 'occupancy' occurs in the evening (at 18:55), not the morning. The mean rise in internal temperature in the second half of the day $\left(3.2^{\circ} \mathrm{C}\right)$ is slightly higher than the mean increase

\footnotetext{
${ }^{6}$ The mean boiler coincidence factor starts to rise before the proportion of homes with occupancy set to IN because of the optimum start feature mentioned above.
}

in the morning period $\left(2.8^{\circ} \mathrm{C}\right.$ ) (see Fig. 8 ), so the higher peak in the morning cannot be explained by a greater temperature increase. ${ }^{7}$ A key factor contributing to the relative height of the morning peak is the synchronous starting of the heating at around 07:00 in many homes, which contrasts with the less synchronous starting up of heating systems in the early evening. This 'staggered start' in the evening spreads the demand for energy over a longer period and underlies the relatively lower peak.

If the interview findings that supplementary heat sources are more likely to be used in the evening can be extrapolated to the whole sample, this would suggest that supplementary heater use is another factor likely to be causing a difference between morning and evening demand patterns. In homes where supplementary heating (such as a wood burner) is the main heat source in the living room in the evening, the demand on the boiler is likely to be lower at this time of day than in the morning. In addition, the evening temperature rise may be partly enabled by solar or internal gains during the day, so reducing the load on the boiler.

\footnotetext{
$\overline{7}$ Patterns of hot water use in the morning do not affect these results which are based on 'call for heat' only.
} 
Influence of technology on patterns of demand

The pattern of demand is mediated by the heating technology. Householders in the UK are familiar with the rapid response of boiler which typically have capacities of $15-40 \mathrm{~kW}$ and flow temperatures around $70{ }^{\circ} \mathrm{C}$ (Orr et al. 2009). Electric heat pumps have lower capacities and output temperatures and it might be expected that usage patterns would be different. ${ }^{8}$ Nevertheless, despite the different operating characteristics of heat pumps, Love et al. (2017) show that demand peaks morning and evening (with the highest peak in the morning) are present among a sample of 696 UK homes with heat pumps. Their simulation of the impact of HPs in $20 \%$ of UK dwellings shows the heat pump demand 'beginning to create a morning peak in the grid load where there was not one before' (Love et al. 2017 p338).

The results described are specific to the UK context of gas boilers as the predominant central heating technology; however, the concepts introduced are also relevant to the analysis of heating use in other countries. Two examples suggest that heating demand also varies in a regular pattern over the day in countries with a much higher proportion of electric heating. Morch et al. (2013, Fig. 4) shows morning and evening peaks in electricity demand for space heating in Norway and modelling for RTE (2016) suggests that domestic space heating demand in France at the peak time of 20:00 is 34\% higher than that at $16: 00$.

\section{Conclusion}

For the group of 337 UK homes in the study, the link between regular practices and the time the heating is switched on in the morning drives a steep increase in heating energy demand between 06:00 and 07:00. The peak coincidence of boiler operation in the morning is higher than that in the evening peak period, which has a less synchronous starting time. This suggests that household thermal routines in the morning are a particularly important consideration for a transition to future energy systems with a high proportion of electric heating such as heat pumps. In order to manage peaks introduced by electrification of heating, there may be a need to change

\footnotetext{
${ }^{8}$ It seems likely that the type of control interface installed also influences user practices. "Learning thermostats" such as NEST (Yang and Newman 2013) and others, could change the patterns of operation.
}

the association of practices in the home and heating operation times, particularly the expectation (very widely held in the UK) that the heating will start at, or shortly before, the time the household get up in the morning.

The interviews for this study identified some households not operating the heating in the middle of the day, even though a resident is normally present at this time. Researchers aiming to model heating energy demand based on time use data should be aware that occupancy times and heating demand patterns do not always match.

The findings of this study are relevant to electricity network operators as they show that user expectations of running patterns may not align with network operator goals for demand management. This poses a challenge for the design of heating systems and controls. How can flexibility be encouraged while ensuring users are able to achieve the conditions they prefer? Changes in the technical configuration of heat delivery systems, for example effective zoning to allow bedroom temperatures to be kept cool, may mitigate the impact of altered operating patterns.

Patterns of heating operation are influenced by the rhythms of daily activities in the home and by expectations of different temperatures at different times of day. The concept of thermal routines is proposed as a framework for examining the limits of flexibility of heating demand and exploring why users might be reluctant to adopt 'technically optimum' operating patterns.

Acknowledgements This research was made possible by support from the EPSRC Centre for Doctoral Training in Energy Demand (LoLo), grant numbers EP/L01517X/1 and EP/ H009612/1, and with financial support from PassivSystems Ltd.

\section{Compliance with ethical standards}

Conflict of interest Clare Hanmer has received research funding from PassivSystems Ltd. (as noted in acknowledgements).

Edwin Carter is employed by PassivSystems Ltd. (as noted in affiliations).

Informed consent Research plans were reviewed and approved by the Department Ethics Director. PassivSystems customers who volunteered to take part in interviews were informed of the purpose of the research and gave consent to anonymised data from interviews being published. They are referred to by pseudonyms in this paper.

Open Access This article is distributed under the terms of the Creative Commons Attribution 4.0 International License (http:// creativecommons.org/licenses/by/4.0/), which permits unrestricted use, distribution, and reproduction in any medium, provided 
you give appropriate credit to the original author(s) and the source, provide a link to the Creative Commons license, and indicate if changes were made.

\section{References}

Akrich, M., 1992. The de-Scription of technical objects in Bijker and law (eds.) shaping technology/building society: Studies in sociotechnical change.

ASHRAE. (2013). Thermal environmental conditions for human occupancy. In ASHRAE standard 55-2013. ASHRAE: Atlanta, Ga.

Chan, A., Moreno, J., Hughes, M., 2014. Further analysis of data from the HEUS electricity price signals and demand response.

de Dear, R., Leow, K. G., \& Foo, S. C. (1991). Thermal comfort in the humid tropics: Field experiments in air conditioned and naturally ventilated buildings in Singapore. International Journal of Biometeorology, 34, 259-265.

DECC, 2012. Emissions from heat: Statistical summary. https:/www.gov.uk /government/uploads /system / uploads / attachment data /file /140095 /4093-emissions-heat-statistical-summary.Pdf.

Delta-ee, 2012. 2050 Pathways for Domestic Heat Final Report 16th October 2012. http://www.enwl.co.uk/about-us/thefuture/nia-lcnf-tier-1/demand-scenarios

Fanger. (1970). Thermal comfort: Analysis and applications in environmental engineering. New York: McGraw-Hill.

Fell, M., 2016. Taking Charge: Perceived control and acceptability of domestic demand-side response ( $\mathrm{PhD}$ thesis). University College London.

Hellwig, R. T. (2015). Perceived control in indoor environments: A conceptual approach. Building Research and Information, 43, 302-315.

Huebner, G. M., McMichael, M., Shipworth, D., Shipworth, M., Durand-Daubin, M., \& Summerfield, A. (2013). Heating patterns in English homes: Comparing results from a national survey against common model assumptions. Building and Environment, 70, 298-305.

Huebner, G. M., McMichael, M., Shipworth, D., Shipworth, M., Durand-Daubin, M., \& Summerfield, A. J. (2015). The shape of warmth: Temperature profiles in living rooms. Building Research and Information, 43, 185-196.

Humphreys, M. A., \& Nicol, J. F. (1998). Understanding the adaptive approach to thermal comfort. ASHRAE transactions. Atlanta, 104, 991.

Judson, E.P., Bell, S., Bulkeley, H., Powells, G. and Lyon, S., 2015. The co-construction of energy provision and everyday practice: Integrating heat pumps in social housing in England. Science \& Technology Studies.

Kane, T., Firth, S. K., \& Lomas, K. J. (2015). How are UK homes heated? A city-wide, socio-technical survey and implications for energy modelling. Energy and Buildings, 86, 817-832.

Kavgic, M., Mavrogianni, A., Mumovic, D., Summerfield, A., Stevanovic, Z., \& Djurovic-Petrovic, M. (2010). A review of bottom-up building stock models for energy consumption in the residential sector. Building and Environment, 45, 1683-1697.

Lader, D., Short, S., \& Gershuny, J. (2006). The time use survey 2005. Oxford: Centre for Time Use Research.
Lefebvre, H. (2004). Rhythmanalysis: Space, time and everyday life. London: Continuum.

Love, J., Smith, A. Z. P., Watson, S., Oikonomou, E., Summerfield, A., Gleeson, C., Biddulph, P., Chiu, L. F., Wingfield, J., Martin, C., Stone, A., \& Lowe, R. (2017). The addition of heat pump electricity load profiles to GB electricity demand: Evidence from a heat pump field trial. Applied Energy, 204, 332-342.

McKenna, E., Krawczynski, M., \& Thomson, M. (2015). Fourstate domestic building occupancy model for energy demand simulations. Energy and Buildings, 96, 30-39.

Morch, A.Z., Saele, H., Feilberg, N, Byskov Lindberg, K 2013 Method for development and segmentation of load profiles for different final customers and appliances ECEEE Summer Study.

Nicol, F., Humphreys, M., \& Roaf, S. (2012). Adaptive thermal comfort: Principles and practice. London: Routledge.

Ofgem, 2016. Electricity system flexibility. https://www.ofgem. gov.uk/electricity/retail-market/ market-review-and-reform /smarter-markets-programme/electricity-system-flexibility.

Orr, G, Lelyveld, T and Burton, S 2009 Final Report: Insitu monitoring of efficiencies of condensing boilers and use of secondary heating. https://www.gov. $\mathrm{uk} /$ government/publications/in-situ-monitoring-ofefficiencies-of-condensing-boilers-and-use-of-secondaryheating-trial-final-report-2009

Oseland, N. A. (1995). Predicted and reported thermal sensation in climate chambers, offices and homes. Energy and Buildings, 23, 105-115.

Owen, A., Mitchell, G., \& Unsworth, R. (2012). Reducing carbon, tackling fuel poverty: Adoption and performance of airsource heat pumps in East Yorkshire, UK. Local Environment, 18(7), 817-833.

Palmer, J., \& Cooper, I. (2014). UK housing energy fact file, 2013.

Reckwitz, A. (2002). Toward a theory of social practices. A Development in Culturalist Theorizing. Eur. J. Soc. Theory, 5, 243-263.

Redpoint, 2013. Modelling to support The Future of Heating: Meeting the Challenge. https://www.gov. uk/government/publications/the-future-of-heatingmeeting-the-challenge

RTE, 2016. Bilan prévisionnel de l'équilibre offre-demande d'électricité en France.

Shipworth, D. (2013). The vernacular architecture of household energy models. Perspectives on Science, 21, 250-266.

Shove, E. (2012). Habits and their creatures. The Habits of consumption, 12, 100-113.

Shove, E. (2003). Comfort, cleanliness and convenience: The social organization of normality, new technologies/new cultures. Oxford: Berg.

Shove, E., \& Walker, G. (2014). What is energy for? Social practice and energy demand. Theory Culture and Society, $31,41-58$.

Shove, E., Trentmann, F., \& Wilk, R. R. (2009). Time, consumption and everyday life: Practice, materiality and culture. Oxford: Berg.

Strbac, G. (2008). Demand side management: Benefits and challenges. Energy Policy, Foresight Sustainable Energy Management and the Built Environment Project, 36, 44194426. 
Strengers, Y. (2013). Smart utopia?: Smart energy technologies in everyday life, consumption and public life Y. New York: Palgrave Macmillan.

Strengers, Y., Nicholls, L., Maller, C., 2014. Curious energy consumers: Humans and nonhumans in assemblages of household practice. Journal of Consumer Culture.

Summerfield, A. J., Oreszczyn, T., Hamilton, I. G., Shipworth, D., Huebner, G. M., Lowe, R. J., \& Ruyssevelt, P. (2015). Empirical variation in 24-h profiles of delivered power for a sample of UK dwellings: Implications for evaluating energy savings. Energy and Buildings, 88, 193-202.

Torriti, J., Hanna, R., Anderson, B., Yeboah, G., \& Druckman, A. (2015). Peak residential electricity demand and social practices: Deriving flexibility and greenhouse gas intensities from time use and locational data. Indoor and Built Environment, 24, 891-912.

Tweed, C., Dixon, D., Hinton, E., \& Bickerstaff, K. (2014). Thermal comfort practices in the home and their impact on energy consumption. Architectural Engineering and Design Management, 10, 1-24.

Yang, R. and Newman, M.W., 2013. Learning from a learning thermostat: Lessons for intelligent systems for the home. In Proceedings of the 2013 ACM international joint conference on Pervasive and ubiquitous computing (pp. 93-102). ACM. Zerubavel, E. (1985). Hidden rhythms: schedules and calendars in social life. Berkeley; London: University of California Press. 